\title{
Valor nutritivo de perfilhos e componentes morfológicos em pastos de capim-braquiária diferidos e adubados com nitrogênio
}

\section{Manoel Eduardo Rozalino Santos ${ }^{1}$, Dilermando Miranda da Fonseca ${ }^{2}$, Eric Márcio Balbino ${ }^{1}$, Simone Pedro da Silva ${ }^{1}$, João Paulo Ismério dos Santos Monnerat ${ }^{1}$}

\footnotetext{
1 Pós-graduação em Zootecnia - Departamento de Zootecnia da Universidade Federal de Viçosa. Bolsista do CNPq.

2 Departamento de Zootecnia da Universidade Federal de Viçosa.
}

RESUMO - Este trabalho foi realizado com o objetivo de avaliar o valor nutritivo de perfilhos e componentes morfológicos em pastos diferidos e adubados com nitrogênio de Brachiaria decumbens cv. Basilisk. Dois experimentos foram realizados em delineamento de blocos casualizados com três repetições e esquema de parcela subdivida. No primeiro experimento, foram realizadas combinações entre doses de nitrogênio (0, 40, 80 e $120 \mathrm{~kg} / \mathrm{ha}$ ) com os componentes morfológicos (folha verde, colmo verde, folha morta e colmo morto) ou com as categorias de perfilhos (vegetativo e reprodutivo) do pasto. No segundo experimento, estudaram-se as combinações entre períodos de diferimento (73, 95 e 116 dias) com categorias de perfilhos (vegetativo e reprodutivo). A adubação nitrogenada aumentou o percentual de fibra em detergente neutro (FDN) nos colmos verdes e o teor de proteína bruta (PB) nas folhas verdes e mortas e no colmo verde. Elevou também os percentuais de PB nos perfilhos vegetativos e reprodutivos, assim como o teor de FDN do perfilhos vegetativos. Maior período de diferimento causou acréscimo no percentual de FDN e redução no percentual de proteína bruta nos perfilhos vegetativos e reprodutivos. A dose de nitrogênio e o período de diferimento alteram o valor nutritivo dos componentes morfológicos e dos perfilhos dos pastos de B. decumbens cv. Basilisk. No diferimento da pastagem, ações de manejo que resultem em maiores percentuais de lâmina foliar verde e perfilho vegetativo no pasto contribuem para melhorar o valor nutritivo da forragem diferida.

Palavras-chave: Brachiaria decumbens, colmo, lâmina foliar, perfilho reprodutivo, perfilho vegetativo, período de diferimento

\section{Nutritive value of tillers and morphological components on deferred and nitrogen fertilized pastures of Brachiaria decumbens cv. Basilisk}

\begin{abstract}
This work was carried out aiming to evaluate the nutritional value of tillers and the morphological components on deferred and nitrogen-fertilized pastures of Brachiaria decumbens cv. Basilisk. Two experiments were performed in randomized block designs with three repetitions and subdivided plot scheme. In the first experiment, combinations among nitrogen doses (0,40, 80 and $120 \mathrm{~kg} / \mathrm{ha}$ ) were performed either with the morphological components (green leaves, green stem, dead leaves and dead stem) or with tiller categories (vegetative and reproductive) of the pasture. In the second experiment, the combinations of the deferring periods (73, 95 and 116 days) with the tiller categories (vegetative and reproductive) were studied. $\mathrm{N}$-fertilization increased neutral detergent fiber (NDF) percentage in the green stem and the content of crude protein (CP) in green leaves, dead leaves, and green stem. N-fertilization also increased CP percentages in the vegetative and reproductive tillers, as well as the NDF content in vegetative tillers. A higher deferring period resulted in an increment of the NDF percentage and a reduction of crude protein percentage in the vegetative and reproductive tillers. Nitrogen dose and the deferring period alter the nutritional value of the morphological components and the tillers of the pastures of B. decumbens cv. Basilisk. For deferring of pastures, management actions that result in higher percentages of green foliar blade and vegetative tiller in the pasture contribute to improve the nutritional value of the deferred forage.
\end{abstract}

Key Words: Brachiaria decumbens, deferring period, foliar blade, reproductive tiller, stem, vegetative tiller

\section{Introdução}

Para contornar o período de limitada quantidade de forragem nas pastagens, a Brachiaria decumbens pode ser utilizada sob pastejo diferido, que em geral consiste em estratégia de fácil implementação e de baixo custo, razão pela qual é muito adotada pelos pecuaristas. Características como produção de forragem satisfatória durante o outono, colmo delgado e perda do valor nutritivo menos intensa durante o crescimento, fazem da 
B. decumbens uma forrageira adequada para o manejo sob pastejo diferido.

Apesar de garantir um estoque de forragem para ser utilizado sob pastejo durante os meses de inverno, o diferimento do uso da pastagem resulta em produção de forragem de limitado valor nutritivo (Santos et al., 2008). Para reduzir esse problema, algumas ações de manejo podem ser empregadas, como a utilização de menor período de diferimento do pasto e a adubação nitrogenada no início do período de diferimento.

As ações de manejo geram modificações nas características estruturais do pasto diferido e, dentre elas, mudanças na densidade populacional de perfilhos e nas características de perfilhos individuais. Assumindo que o pasto é constituído por uma população de perfilhos, o conhecimento destes pode permitir inferências sobre o pasto diferido. Assim, a caracterização do valor nutritivo de perfilhos pode auxiliar a compreensão das causas da limitada qualidade da forragem produzida com as ações de manejo adotadas no diferimento.

Da mesma forma, o entendimento sobre a maneira como as ações de manejo empregadas no diferimento da pastagem, especialmente a adubação nitrogenada e a duração do período de diferimento, influenciam o valor nutritivo dos componentes morfológicos do pasto também é relevante, embora pouco estudado. De fato, maior ênfase tem sido dada à quantificação da massa desses componentes morfológicos na forragem e à comparação do valor nutritivo entre os mesmos, porém estudos sobre as alterações no valor nutritivo de um mesmo componente morfológico em situações diferenciadas de manejo são incipientes, senão, inexistentes em condições de pastagens diferidas.

Estudou-se o valor nutritivo de perfilhos vegetativos e reprodutivos e dos componentes morfológicos de pastos de Brachiaria decumbens cv. Basilisk sob períodos de diferimento e doses de nitrogênio.

\section{Material e Métodos}

Dois experimentos foram conduzidos de janeiro a julho de 2006 numa área de pastagem de Brachiaria decumbens cv. Basilisk (Stapf.), com $540 \mathrm{~m}^{2}$, pertencente ao Setor de Forragicultura do Departamento de Zootecnia da Universidade Federal de Viçosa (UFV), localizada em Viçosa, Minas Gerais (2045' S; 4251' W; 651 m). O solo da área experimental é um latossolo vermelho-amarelo de textura argilosa. A análise química do solo, realizada no início do período experimental, na camada $0-20 \mathrm{~cm}$, apresentou os seguintes resultados: $\mathrm{pH}$ em $\mathrm{H}_{2} \mathrm{O}: 5,4 ; \mathrm{P}: 1,5$ (Mehlich-1) e $\mathrm{K}: 115 \mathrm{mg} / \mathrm{dm}^{3} ; \mathrm{Ca}^{2+}: 1,8 ; \mathrm{Mg}^{2+}: 0,7 \mathrm{e} \mathrm{Al}^{3+}: 0,2 \mathrm{cmol}_{\mathrm{c}} / \mathrm{dm}^{3}$ (KCl $1 \mathrm{~mol} / \mathrm{L})$. Durante o período de avaliação, foram registrados dados climáticos em estação meteorológica distante da área experimental aproximadamente $500 \mathrm{~m}$ (Tabela 1).

No primeiro experimento, foi avaliado o efeito da adubação nitrogenada sobre o valor nutritivo de perfilhos ou de componentes morfológicos do pasto de capimbraquiária diferido por 95 dias. O experimento seguiu delineamento em blocos casualizados com três repetições, em esquema de parcela subdividida com quatro níveis de nitrogênio ( 0,40 , 80 e $120 \mathrm{~kg} / \mathrm{ha})$ e quatro componentes morfológicos do pasto (folha verde, folha morta, colmo verde e colmo morto) ou duas categorias de perfilhos (vegetativo e reprodutivo). Cada parcela media $12,38 \mathrm{~m}^{2} \mathrm{e}$, descontando-se a área de bordadura, possuía uma área útil de 5,25 $\mathrm{m}^{2}$. O nitrogênio foi aplicado na data de início do período de diferimento (28/3/2006) em dose única, na forma de uréia e ao final da tarde. Em seguida, as parcelas foram irrigadas apenas para incorporação do adubo nitrogenado visando reduzir as possíveis perdas de nitrogênio por volatilização.

No segundo experimento, avaliou-se o efeito do período de diferimento sobre o valor nutritivo de perfilhos em pastos de capim-braquiária. O experimento seguiu

Tabela 1 - Médias mensais da temperatura média diária, insolação, precipitação pluvial total e evaporação total durante o período de janeiro a julho de 2006

\begin{tabular}{lcccc}
\hline Mês & Temperatura média do ar $\left({ }^{\circ} \mathrm{C}\right)$ & Insolação (hora/dia) & Precipitação pluvial $(\mathrm{mm})$ & Evaporação $(\mathrm{mm})$ \\
\hline Janeiro & 23,1 & 7,2 & 180,0 & 108,6 \\
Fevereiro & 23,6 & 9,4 & 84,8 & 82,4 \\
Março & 22,6 & 5,6 & 186,5 & 62,5 \\
Abril & 20,7 & 5,3 & 56,0 & 5,4 \\
Maio & 17,2 & 5,3 & 21,0 & 6,0 \\
Junho & 16,1 & 5,1 & 6,3 & 79,4 \\
Julho & 15,7 & 6,5 & & 79,0 \\
\hline
\end{tabular}


delineamento em blocos casualizados com três repetições, em esquema de parcela subdividida com três períodos de diferimento (73, 95 e 116 dias) e duas categorias de perfilhos (vegetativo e reprodutivo). No início do período de diferimento foi aplicado $80 \mathrm{~kg} / \mathrm{ha}$ de $\mathrm{N}$, em cobertura, no fim da tarde e na forma de uréia. As dimensões das unidades experimentais foram iguais às do experimento anterior. Para implementação dos distintos períodos de diferimento dos pastos, as parcelas foram diferidas em épocas diferentes, quais sejam: 7/3/2006, 28/3/2006 e 194/2006; e o período de diferimento encerrado em única data (1/7/2006).

Em ambos os experimentos, a altura dos pastos foi monitorada semanalmente e mantida em aproximadamente $20 \mathrm{~cm}$ até o início do diferimento. Para isso, adotou-se a técnica de mob-grazing, com grupos de bovinos para desfolhações rápidas, mimetizando um cenário de pastejo. A adubação fosfatada foi efetuada no dia 6 de janeiro de 2006, com a aplicação de $50 \mathrm{~kg} /$ ha de $\mathrm{P}_{2} \mathrm{O}_{5}$, na forma de superfosfato simples, em toda área experimental. Os pastos permaneceram diferidos até o dia 1/7/2006, data considerada apropriada para iniciar a utilização dos pastos diferidos de capim-braquiária na região de Viçosa, Minas Gerais (Santos et al., 2009a). Nessa data também foram realizadas todas as amostragens de perfilhos e componentes morfológicos do pasto diferido.

Apenas no primeiro experimento, a massa dos componentes morfológicos do pasto foi determinada pela amostragem, ao nível do solo, de todos os perfilhos contidos no interior de um quadrado de $50 \mathrm{~cm}$ de lado em uma área representativa da condição média do pasto em cada parcela. As amostras foram acondicionadas em saco plástico e, no laboratório, separadas manualmente em folha verde, colmo verde, folha morta e colmo morto. A inflorescência e a bainha foliar verdes foram incorporadas à fração colmo verde. A parte da lâmina foliar que não apresentava sinais de senescência (órgão de cor verde) foi incorporada à fração folha verde. As partes do colmo e da lâmina foliar senescentes e mortas (com amarelecimento e, ou necrosamento do órgão) foram incorporadas à fração colmo morto e folha morta, respectivamente. Os componentes morfológicos foram pesados e secos em estufa de circulação forçada de ar a $65^{\circ} \mathrm{C}$, por 72 horas. Depois de retirados da estufa, foram pesados novamente.

Em ambos os experimentos, foram colhidas, rente ao solo e em locais que representavam a condição média das plantas, duas amostras por parcela, constituídas de 50 perfilhos vegetativos e 50 perfilhos reprodutivos. Os perfilhos vivos que tinham a inflorescência visível foram classificados como reprodutivos e aqueles vivos que não tinham a inflorescência visível foram denominados de vegetativos. As amostras devidamente identificadas foram levadas para o laboratório, pesadas e colocadas em estufa de ventilação forçada de ar por 72 horas a $65^{\circ} \mathrm{C}$. Posteriormente, as amostras foram pesadas novamente.

Todas as amostras tiveram seus teores de matéria seca (MS), fibra em detergente neutro (FDN) e compostos nitrogenados totais (PB) determinados de acordo com as técnicas descritas por Silva \& Queiroz (2002). A fibra em detergente neutro indigestível (FDNi) foi estimada por intermédio da digestibilidade in situ, por 240 horas no rúmen de vacas fistuladas da raça holandesa. A fibra em detergente neutro potencialmente digestível (FDNpoD) e a matéria seca potencialmente digestível (MSpoD) foram calculadas de acordo com Paulino et al. (2006).

Para cada característica foi realizada análise de variância e, posteriormente, análise de regressão para expressar os efeitos das parcelas (doses de nitrogênio e períodos de diferimento no primeiro e no segundo experimento, respectivamente) dentro das subparcelas (tipos dos componentes morfológicos e categorias de perfilhos no primeiro experimento, e apenas categoria de perfilhos no segundo experimento), cujo maior modelo de superfície de resposta em função das médias dos fatores em estudo foi o seguinte: $Y_{i}=\beta_{0}+\beta_{1} X_{i}+e_{i}$, em que: $Y_{i}=$ variável-resposta; $X_{i}=$ variável independente; $\beta_{0}, \beta_{1}=$ parâmetros a ser estimados; $\mathrm{e}_{\mathrm{i}}=$ erro experimental.

No primeiro experimento, a variável independente correspondeu à dose de nitrogênio, enquanto que no segundo experimento a variável independente foi o período de diferimento. O grau de ajustamento dos modelos foi avaliado pelo coeficiente de determinação e pela significância dos coeficientes de regressão, testada pelo teste t corrigido com base nos resíduos da análise de variância.

Nos dois experimentos, os níveis dos fatores qualitativos (componente morfológico ou categoria de perfilho), que constituíram a subparcela, foram comparados pelo teste de Tukey dentro de cada nível dos fatores quantitativos (dose de nitrogênio ou período de diferimento), que corresponderam à parcela. Todas as análises estatísticas foram realizadas usando o Sistema para Análises Estatísticas - SAEG, versão 8.1 (UFV, 2003) em nível de significância de até $10 \%$ de probabilidade.

\section{Resultados e Discussão}

A comparação entre os componentes morfológicos do pasto diferido evidenciou que a folha verde possuiu $(\mathrm{P}<0,10)$ os menores teores de fibra em detergente neutro e de fibra em detergente neutro indigestível, e maiores valores para 
percentual de matéria seca potencialmente digestível e proteína bruta, independentemente da dose de nitrogênio utilizada (Tabela 2). O nitrogênio faz parte da composição de diversas moléculas envolvidas na fotossíntese, como a rubisco e a fosfoenolpiruvato-carboxilase (Santos, 2004), processo que ocorre, principalmente, nas células do mesófilo foliar (Corsi \& Nascimento Jr., 1994). Isso explica o maior teor de proteína bruta da folha verde. Ademais, a folha é constituída, em sua maior proporção, de tecidos de parede celular delgada (Pacciulo et al., 2002), conferindo à mesma menor percentual de fibra em detergente neutro e fibra em detergente neutro indigestível.

Por outro lado, o colmo, especialmente o colmo morto, foi $(\mathrm{P}<0,10)$ o componente morfológico do pasto diferido de pior valor nutritivo, contendo, de forma geral, os menores percentuais de fibra em detergente neutro potencialmente digestível, matéria seca potencialmente digestível e proteína bruta e os maiores teores de fibra em detergente neutro indigestível (Tabela 2). O elevado percentual de fibra em detergente neutro indigestível do colmo morto pode ter sido causado pela sua oxidação parcial realizada por fungos e bactérias presentes na superfície desses órgãos durante o processo de senescência. Com isso, pode ter ocorrido maior concentração de fibra indigestível, em detrimento da fibra mais digestível.

Os menores teores de proteína bruta no colmo morto podem ser explicados pela translocação de compostos solúveis, como o nitrogênio, durante o processo de senescência. Nesse processo, o nitrogênio também pode ser utilizado na respiração do próprio órgão em senescência ou por bactérias e fungos que vivem sobre o tecido vegetal (Pedreira et al., 2001). Os efeitos concomitantes de redução na proteína bruta e de elevação na fibra em detergente neutro indigestível contribuíram para diminuir a matéria seca potencialmente digestível do colmo morto.

A análise conjunta dos dados permite ordenar os componentes morfológicos do pasto diferido de capimbraquiária, na seqüência de melhor para pior valor nutritivo, da seguinte forma: folha verde, folha morta, colmo verde e colmo morto. Esses resultados eram esperados e também foram descritos em trabalhos realizados com outras gramíneas tropicais e em situações de manejo distintas (Santos et al., 2008; Paciullo et al., 2001; Difante et al., 2009). Isso salienta a necessidade de adotar estratégias de manejo no pastejo diferido que priorizem a produção de tecido foliar em detrimento do acúmulo de colmo; e reduzam a senescência

Tabela 2 - Valor nutritivo dos componentes morfológicos de capim-braquiária diferido e adubado com nitrogênio

\begin{tabular}{|c|c|c|c|c|c|c|}
\hline \multirow[t]{2}{*}{ Componente morfológico } & \multicolumn{4}{|c|}{ Dose de nitrogênio (kg/ha) } & \multirow[t]{2}{*}{ Regressão } & \multirow[t]{2}{*}{$\mathrm{R}^{2}$} \\
\hline & 0 & 40 & 80 & 120 & & \\
\hline \multicolumn{7}{|c|}{ Fibra em detergente neutro } \\
\hline Folha verde & $63,65 b$ & $61,74 \mathrm{c}$ & $65,28 b$ & $62,50 \mathrm{c}$ & $\overline{\mathrm{Y}}=63,29$ & - \\
\hline Folha morta & $78,51 \mathrm{a}$ & $76,95 b$ & $78,41 \mathrm{a}$ & $76,20 \mathrm{~b}$ & $\overline{\mathrm{Y}}=77,52$ & - \\
\hline Colmo verde & $80,98 a$ & $80,4 \mathrm{ab}$ & $82,33 a$ & $82,95 a$ & $\underline{Y}=80,479+0,01966 * N$ & 0,61 \\
\hline Colmo morto & $83,11 \mathrm{a}$ & $85,55 a$ & $83,37 a$ & $84,85 a$ & $\overline{\mathrm{Y}}=84,22$ & - \\
\hline \multicolumn{7}{|c|}{ Fibra em detergente neutro indigestível } \\
\hline Folha verde & $16,81 \mathrm{c}$ & $16,06 \mathrm{c}$ & $13,98 b$ & $16,08 b$ & $\bar{Y}=15,73$ & - \\
\hline Folha morta & $28,5 b c$ & $25,3 \mathrm{bc}$ & $22,26 b$ & $23,4 \mathrm{ab}$ & $\hat{Y}=27,596-0,04550 * N$ & 0,62 \\
\hline Colmo verde & $35,1 \mathrm{ab}$ & $35,69 b$ & $40,60 \mathrm{a}$ & $39,03 a$ & $\bar{Y}=37,61$ & - \\
\hline Colmo morto & $51,09 a$ & $55,23 a$ & $47,62 \mathrm{a}$ & $38,10 \mathrm{a}$ & $\hat{Y}=54,975-0,11689 * N$ & 0,52 \\
\hline \multicolumn{7}{|c|}{ Fibra em detergente neutro potencialmente digestível } \\
\hline Folha verde & $46,84 \mathrm{a}$ & $45,7 \mathrm{ab}$ & $51,3 a b$ & $46,42 \mathrm{a}$ & $\overline{\mathrm{Y}}=47,56$ & - \\
\hline Folha morta & $50,00 \mathrm{a}$ & $51,69 a$ & $56,15 a$ & $52,77 a$ & $\underline{\bar{Y}}=52,65$ & - \\
\hline Colmo verde & $45,88 \mathrm{a}$ & $44,7 \mathrm{ab}$ & $41,7 \mathrm{ab}$ & $43,92 \mathrm{a}$ & $\overline{\mathrm{Y}}=44,05$ & - \\
\hline Colmo morto & $32,03 a$ & $27,44 b$ & $35,95 b$ & $46,74 \mathrm{a}$ & $\hat{Y}=27,642+0,00132^{*} \mathrm{~N}$ & 0,52 \\
\hline \multicolumn{7}{|c|}{ Matéria seca potencialmente digestível } \\
\hline Folha verde & $82,46 a$ & $83,18 \mathrm{a}$ & $85,32 \mathrm{a}$ & $83,17 \mathrm{a}$ & $\bar{Y}=83,53$ & - \\
\hline Folha morta & $71,1 \mathrm{ab}$ & $74,3 \mathrm{ab}$ & $77,31 \mathrm{a}$ & $76,1 \mathrm{ab}$ & $\underline{Y}=71,9711+0,045 * N$ & 0,61 \\
\hline Colmo verde & $64,5 b c$ & $63,92 b$ & $59,05 b$ & $60,63 b$ & $\overline{\mathrm{Y}}=62,03$ & - \\
\hline Colmo morto & $48,58 c$ & $44,42 c$ & $52,25 b$ & $61,59 b$ & $\hat{Y}=44,6776+0,1172 * N$ & 0,52 \\
\hline \multicolumn{7}{|c|}{ Proteína bruta } \\
\hline Folha verde & $5,91 \mathrm{a}$ & $6,26 \mathrm{a}$ & $6,74 a$ & 8,13a & $\hat{Y}=5,6928+0,0178 * N$ & 0,84 \\
\hline Folha morta & $2,25 b$ & $2,58 b$ & $2,56 b$ & $3,39 b$ & $\hat{Y}=2,1880+0,0085 * N$ & 0,72 \\
\hline Colmo verde & $2,10 \mathrm{~b}$ & $2,48 b$ & $2,55 b$ & $2,96 b$ & $\underline{\hat{Y}}=2,1259+0,0066 * N$ & 0,91 \\
\hline Colmo morto & $1,61 b$ & $1,91 b$ & $1,59 c$ & $2,08 \mathrm{c}$ & $\overline{\mathrm{Y}}=1,80$ & - \\
\hline
\end{tabular}

Médias seguidas pela mesma letra na coluna não diferem $(P>0,10)$ pelo teste Tukey.

* Significativo pelo teste $\mathrm{t}(\mathrm{P}<0,10)$. 
e morte de folhas e perfilhos. Nesse sentido, ações como redução no período em que o pasto permanece diferido e realização da adubação com nitrogênio podem contribuir para a ocorrência de maior massa de folha verde e menores massas de colmo e material morto na forragem diferida (Santos et al., 2009b), sendo, portanto, ações recomendadas para, dentre outros fatores, melhorar o valor nutritivo da forragem diferida em algumas regiões.

A adubação com nitrogênio resultou na elevação linear $(\mathrm{P}<0,10)$ dos teores de proteína bruta da folha verde em $38 \%$ (Tabela 2). A maior disponibilidade de nitrogênio no solo resulta em sua maior absorção pela planta e maior concentração no tecido vegetal, especialmente no tecido foliar verde. As demais características de valor nutritivo avaliadas na folha verde não foram influenciadas $(\mathrm{P}>0,10)$ pela adubação nitrogenada (Tabela 2). O principal efeito da adubação com nitrogênio no pasto é o aumento do fluxo de tecidos (Nascimento Jr. \& Adese, 2004), de forma que as características de folhas individuais não são, geralmente, muito modificadas. Isso explica a ausência de resposta da folha verde à aplicação de nitrogênio para a maioria das características de valor nutritivo mensuradas, exceto para o teor de proteína bruta.

A adubação nitrogenada reduziu linearmente $(\mathrm{P}<0,10)$ o teor de fibra em detergente neutro indigestível e incrementou $(\mathrm{P}<0,10)$ os teores de matéria seca potencialmente digestível e proteína bruta na folha morta. A aplicação de nitrogênio também melhorou o valor nutritivo do colmo morto, haja vista que elevou $(\mathrm{P}<0,10)$ seus percentuais de fibra em detergente neutro potencialmente digestível e matéria seca potencialmente digestível, bem como reduziu $(\mathrm{P}<0,10)$ o de fibra em detergente neutro indigestível (Tabela 2). Possivelmente, o aumento da concentração de proteína bruta nesses tecidos mortos pode ter favorecido a atividade dos microrganismos fibrolíticos, estimulando a degradação e o aproveitamento da fibra em detergente neutro, com conseqüente melhoria no potencial de utilização da massa seca desses componentes morfológicos.

O colmo verde teve os percentuais de fibra em detergente neutro $(\mathrm{P}<0,10)$ e proteína bruta $(\mathrm{P}<0,10)$ aumentados linearmente com a elevação das doses de nitrogênio (Tabela 2). O incremento do teor de proteína bruta no colmo verde se deve à maior disponibilidade desse nutriente no solo, o que proporciona sua maior absorção pela planta. O maior crescimento do capim-braquiária com a aplicação de nitrogênio resulta em plantas mais altas e com maiores números de fitômeros, o que torna necessário que o colmo seja mais rígido e espesso para sustentar o peso da planta (Santos et al., 2009c). Para isso, o colmo passa a conter maior percentual de tecidos estruturais de sustentação, com parede celular mais espessa, tais como o esclerênquima e xilema. Como a fibra em detergente neutro engloba os compostos da parede celular, dentre eles a proteína insolúvel, a hemicelulose, a lignina e a celulose (Van Soest, 1994), fica elucidado o seu aumento com a aplicação de maiores doses de nitrogênio.

Das vinte equações de regressão possíveis de serem obtidas para as respostas dos componentes morfológicos à adubação com nitrogênio, apenas nove foram adequadamente ajustadas aos dados experimentais (Tabela 2). Ademais, os coeficientes angulares das equações ajustadas são de pequenas magnitudes (em média, igual a 0,02\% para cada quilograma de nitrogênio aplicado). Realmente, é consenso que o principal efeito da adubação nitrogenada ocorre no aumento da produção de forragem por unidade de área da pastagem e não na melhoria do valor nutritivo da forragem. Contudo, vale sublinhar que a adubação nitrogenada também pode alterar a massa de cada componente morfológico no pasto diferido (Santos et al., 2009b) e isso pode modificar de forma mais efetiva o valor nutritivo da forragem diferida.

Mesmo a folha verde, componente morfológico do pasto de maior teor de proteína bruta, possuiu, em média, teor abaixo de 7,00\%, valor tido como mínimo para atender as exigências nutricionais dos microrganismos ruminais (Van Soest, 1994). Como o pasto diferido não é constituído somente por folha verde, é certo que a forragem resultante do diferimento da pastagem, independente da dose de nitrogênio aplicada, possuiu teor de proteína bruta limitante. Nesse sentido, para otimizar o consumo e o desempenho animal, a suplementação do pasto diferido é estratégia de manejo recomendada, quando possível, a fim de fornecer nutrientes limitantes no pasto, como o nitrogênio (Paulino et al., 2006).

O teor de matéria seca potencialmente digestível da fração folha morta foi, em geral, superior ao obtido na fração colmo verde (Tabela 2). Desse modo, o potencial de digestão da folha morta pode ser considerado relativamente maior que o do colmo verde. Santos et al. (2004) constatou que a concentração de carboidratos na "fração indigestível” de folha morta de pastagem diferida de Brachiaria decumbens foi 40,8\% menor que a encontrada nos colmo verde e concluiu que a folha morta constitui alimento energético com potencial razoável para o animal durante o período de seca.

Constatou-se que os perfilhos vegetativos são $(\mathrm{P}<0,10)$, em geral, de melhor valor nutritivo do que os perfilhos reprodutivos, porque os primeiros possuem maiores percentuais de matéria seca potencialmente digestível e 
proteína bruta, e menores teores de fibra em detergente neutro indigestível (Tabela 3). Isso se deve ao característico alongamento do colmo verificado quando o perfilho passa do estádio vegetativo para o reprodutivo, o que faz com que a relação folha/colmo seja normalmente menor no perfilho reprodutivo. Esse fato serve de argumento para a adoção de estratégias de manejo no diferimento da pastagem que estimulem surgimento de perfilho vegetativo, bem como evitem o desenvolvimento deste em perfilho reprodutivo. Dentre tais ações de manejo, destacam-se a redução no período de diferimento do pasto, a adubação com nitrogênio (Santos et al., 2009c) e a realização de pastejo mais intenso nos dias que antecedem o período de diferimento do pasto (Paulino et al., 2001). Essas recomendações são válidas quando o diferimento da pastagem é adotado com o objetivo de garantir alimento para o período de escassez de recurso forrageiro. Contrariamente, caso o diferimento seja empregado para auxiliar na recuperação da pastagem, torna-se necessário a produção de sementes oriundas de perfilho reprodutivo para promover a ressemeadura natural na área.

É relevante destacar, ainda, que os perfilhos reprodutivos tendem a morrer, seguindo seu ciclo fenológico normal, originando perfilhos mortos que certamente são de pior valor nutritivo, na medida em que são compostos apenas por lâminas foliares e colmos mortos, componentes morfológicos do pasto de pior valor nutritivo (Tabela 2).

Observou-se também que a diferença de valor nutritivo entre perfilhos vegetativos e reprodutivos foi dependente da dose de nitrogênio aplicada, exceto quando a análise foi feita para o teor de proteína bruta (Tabela 3). Na maior dose de nitrogênio estudada (120 kg/ha), houve semelhança
$(\mathrm{P}>0,10)$ entre essas categorias de perfilhos. Entretanto comportamento distinto foi verificado quando essa comparação foi realizada nas menores doses de nitrogênio aplicadas. Isto é atribuído, dentre outros fatores, ao efeito da adubação nitrogenada no comprimento do colmo do perfilho vegetativo, aumentando-o (Santos et al., 2009c) e fazendo com que a relação folha/colmo do perfilho vegetativo diminua, tornando-se semelhante à do perfilho reprodutivo. Essa similar composição morfológica dos perfilhos resulta em valores nutritivos semelhantes entre perfilho vegetativo e perfilho reprodutivo. De outra forma, quando doses menores de nitrogênio são utilizadas, menor é a taxa de crescimento do perfilho vegetativo e menor é o comprimento do seu colmo (Santos et al., 2009c), condição que o torna mais diferente morfologicamente do perfilho reprodutivo. Novamente, essas diferenças morfológicas resultam em diferenças de valor nutritivo. Fica, portanto, evidente que em pastagens diferidas é possível que perfilhos vegetativos e reprodutivos sejam caracterizados por valor nutritivo semelhante. Essa é uma situação incomum na maioria das condições de manejo das gramíneas forrageiras, onde, via de regra, o perfilho vegetativo é de melhor qualidade do que o perfilho reprodutivo.

Salienta-se, contudo, a superioridade do perfilho vegetativo em relação ao perfilho reprodutivo no que se refere ao percentual de proteína bruta $(\mathrm{P}<0,10)$, o que se deve, provavelmente, ao fato do perfilho vegetativo ainda não ter completado seu ciclo fenológico. Nesse estádio, ocorre síntese de tecidos no perfilho vegetativo, o que permite inferir que reações de anabolismo estejam ocorrendo, com conseqüente absorção de nutrientes, dentre eles o

Tabela 3 - Valor nutritivo de perfilhos em pastos de capim-braquiária diferidos e adubados com nitrogênio

\begin{tabular}{|c|c|c|c|c|c|c|}
\hline \multirow[t]{2}{*}{ Categoria de perfilho } & \multicolumn{4}{|c|}{ Dose de nitrogênio (kg/ha) } & \multirow[t]{2}{*}{ Regressão } & \multirow[t]{2}{*}{$\mathrm{R}^{2}$} \\
\hline & 0 & 40 & 80 & 120 & & \\
\hline \multicolumn{7}{|c|}{ Fibra em detergente neutro } \\
\hline Vegetativo & $68,93 b$ & $70,21 \mathrm{a}$ & $71,12 b$ & $75,10 \mathrm{a}$ & $\hat{Y}=68,429+0,0485^{*} \mathrm{~N}$ & 0,89 \\
\hline Reprodutivo & $74,98 \mathrm{a}$ & $71,78 \mathrm{a}$ & $74,85 a$ & $74,50 \mathrm{a}$ & $\overline{\mathrm{Y}}=74,03$ & - \\
\hline \multicolumn{7}{|c|}{ Fibra em detergente neutro indigestível } \\
\hline Vegetativo & $25,20 \mathrm{~b}$ & $24,81 b$ & $23,37 b$ & $28,74 a$ & $\overline{\mathrm{Y}}=25,53$ & - \\
\hline Reprodutivo & $29,83 a$ & $30,33 a$ & $31,76 a$ & $28,23 a$ & $\overline{\mathrm{Y}}=30,04$ & - \\
\hline \multicolumn{7}{|c|}{ Fibra em detergente neutro potencialmente digestível } \\
\hline Vegetativo & $43,73 a$ & $45,41 \mathrm{a}$ & $47,75 \mathrm{a}$ & $46,36 a$ & $\underline{\bar{Y}}=45,81$ & - \\
\hline Reprodutivo & $45,15 a$ & $41,45 a$ & 43,09a & $46,27 a$ & $\bar{Y}=43,99$ & - \\
\hline \multicolumn{7}{|c|}{ Matéria seca potencialmente digestível } \\
\hline Vegetativo & $74,18 \mathrm{a}$ & $74,60 \mathrm{a}$ & $76,05 a$ & $70,76 a$ & $\overline{\mathrm{Y}}=73,90$ & - \\
\hline Reprodutivo & $69,67 b$ & $69,11 b$ & $67,74 b$ & $71,26 a$ & $\overline{\mathrm{Y}}=69,42$ & - \\
\hline \multicolumn{7}{|c|}{ Proteína bruta } \\
\hline Vegetativo & $3,62 \mathrm{a}$ & $3,61 \mathrm{a}$ & $3,66 \mathrm{a}$ & $3,85 a$ & $\hat{Y}=3,500+0,074 * N$ & 0,73 \\
\hline Reprodutivo & $2,82 b$ & $2,83 b$ & $2,93 b$ & $2,88 b$ & $\hat{Y}=2,795+0,028 * N$ & 0,51 \\
\hline
\end{tabular}

Médias seguidas pela mesma letra na coluna não diferem pelo teste Tukey $(\mathrm{P}>0,10)$; * Significativo pelo teste $\mathrm{t}(\mathrm{P}<0,10)$. 
nitrogênio. Já no perfilho reprodutivo, após seu pleno florescimento, não ocorre mais síntese de tecidos e o próximo evento do seu ciclo fenológico é a senescência e morte. Dessa forma, a atividade metabólica do perfilho reprodutivo tende a reduzir, diminuindo também a absorção de nutrientes como o nitrogênio.

A dose de nitrogênio alterou o percentual de fibra em detergente neutro do perfilho vegetativo (Tabela 3). Maiores doses de nitrogênio resultaram em perfilhos vegetativos mais pesados, com maior comprimento do colmo, que é o órgão da planta rico em tecidos com parede celular espessa, tais como esclerênquima e xilema (Pacciulo et al., 2002). Essa composição de tecidos reflete $(\mathrm{P}<0,10)$ nos teores mais elevados de fibra em detergente neutro quando os perfilhos vegetativos são adubados com altas doses de nitrogênio.

Os dados obtidos no segundo experimento (Tabela 4) confirmam a superioridade $(\mathrm{P}<0,10)$ do perfilho vegetativo em relação ao reprodutivo no que se refere ao valor nutritivo. Maiores $(\mathrm{P}<0,10)$ percentuais de matéria seca potencialmente digestível e proteína bruta, bem como menores $(\mathrm{P}>0,10)$ teores de fibra em detergente neutro e fibra em detergente neutro indigestível, foram constatados no perfilho vegetativo. Isso é consequência de diferenças morfológicas entre as categorias de perfilhos, conforme discutido anteriormente. Considerando que o pasto diferido é constituído por diferentes categorias de perfilhos, parece coerente adotar ações de manejo que favoreçam o surgimento de perfilho vegetativo e impeçam sua diferenciação em perfilho reprodutivo, caso o objetivo seja produzir forragem de melhor qualidade. Dentre essas ações de manejo, destacam-se a redução do período de diferimento do pasto e a adubação nitrogenada no início do período de diferimento (Santos et al., 2009c, d).

Sob maior período de diferimento, houve uma tendência de que os perfilhos vegetativos e reprodutivos se equiparassem em termos de valor nutritivo. Para as cinco características do valor nutritivo avaliadas, quatro (FDN, FDNi, MSpoD e PB) apresentaram diferença $(\mathrm{P}<0,10)$ entre perfilhos quando comparadas no menor período de diferimento (73 dias). Contrariamente, quando a comparação foi realizada no pasto submetido ao maior período de diferimento (116 dias), apenas duas características (FDN e $\mathrm{PB}$ ) foram distintas $(\mathrm{P}<0,10)$ entre os perfilhos (Tabela 4). Períodos de diferimento maiores permitem o maior desenvolvimento do perfilho vegetativo e sua maior diferenciação morfológica, fazendo-o possuir maior número de fitômeros. Isso faz com que os perfilhos vegetativos fiquem em um estádio de desenvolvimento mais próximo do perfilho reprodutivo, ou seja, os perfilhos vegetativos assumem características morfológicas e de valor nutritivo semelhantes ao do perfilho reprodutivo. Nesse contexto, o incremento do período de diferimento não constitui ação de manejo adequada para a melhoria do valor nutritivo da forragem porque, além de seu efeito já conhecido de redução no número de perfilho vegetativo (Santos et al., 2009d), também ocorre diminuição no valor nutritivo do perfilho vegetativo (Tabela 4).

Os perfilhos vegetativos e reprodutivos tiveram teores de fibra em detergente neutro elevados $(\mathrm{P}<0,10)$ e os percentuais de proteína bruta reduzidos $(\mathrm{P}<0,10)$ quando o

Tabela 4 - Valor nutritivo de perfilhos em pastos de capim-braquiária manejados com três períodos de diferimento

\begin{tabular}{|c|c|c|c|c|c|}
\hline Categoria de perfilho & \multicolumn{3}{|c|}{ Período de diferimento (dias) } & Regressão & $\mathrm{R}^{2}$ \\
\hline \multicolumn{6}{|c|}{ Fibra em detergente neutro } \\
\hline Reprodutivo & $73,61 \mathrm{a}$ & $74,85 a$ & 79,33 a & $\hat{Y}=63,3957+0,13239 * D$ & 0,79 \\
\hline \multicolumn{6}{|c|}{ Fibra em detergente neutro indigestível } \\
\hline \multicolumn{6}{|c|}{ Fibra em detergente neutro potencialmente digestível } \\
\hline Vegetativo & $46,37 \mathrm{a}$ & $47,75 a$ & $39,97 a$ & $\overline{\mathrm{Y}}=44,69$ & - \\
\hline Reprodutivo & $41,51 \mathrm{a}$ & $43,09 a$ & $45,80 \mathrm{a}$ & $\hat{Y}=34,0565+0,09939 * \mathrm{D}$ & 0,97 \\
\hline \multicolumn{6}{|c|}{ Matéria seca potencialmente digestível } \\
\hline Vegetativo & $76,42 \mathrm{a}$ & $76,05 a$ & $64,14 a$ & $\underline{\bar{Y}}=72,20$ & - \\
\hline
\end{tabular}

Médias seguidas pela mesma letra na coluna não diferem $(\mathrm{P}>0,10)$ pelo teste Tukey.

* Significativo pelo teste $\mathrm{t}(\mathrm{P}<0,10)$. 
pasto permaneceu diferido por maior período. Nessa condição, os perfilhos tornam-se mais desenvolvidos, possuindo maior peso e tamanho (Santos et al., 2009c), o que implica na necessidade de serem constituídos de tecidos estruturais de sustentação como o esclerênquima, que possui parede celular mais espessa (Pacciulo et al., 2002). A presença de tecidos com parede celular mais espessa é um dos determinantes do alto teor de fibra em detergente neutro desses perfilhos. Além disso, o menor teor de proteína bruta e o maior percentual de fibra em detergente neutro nos perfilhos dos pastos diferidos por maior período é decorrente também da diminuição no percentual de folha e ao aumento no percentual de colmo desses perfilhos (Santos et al., 2009c).

O aumento $(\mathrm{P}<0,10)$ no percentual de fibra em detergente neutro potencialmente digestível do perfilho reprodutivo com o incremento do período de diferimento do pasto não era esperado, uma vez que os perfilhos reprodutivos sob maior período de diferimento são geralmente mais velhos. Estes possuem colmo mais desenvolvido, com maior proporção de esclerênquima (Pacciulo et al., 2002) e maior percentual de lignina (Pacciulo et al., 2001). De fato, tem sido aceito que a lignina é o principal componente químico da parede celular a limitar a digestibilidade das forrageiras.

As modificações nas características de valor nutritivo das categorias de perfilhos em função da dose de nitrogênio (Tabela 3) e do período de diferimento (Tabela 4) foram de maior magnitude para o perfilho vegetativo do que para o reprodutivo. Os fatores de crescimento (tempo e nitrogênio) são mais efetivos em alterar as características daqueles perfilhos que se encontram em estádio de desenvolvimento menor, como os perfilhos vegetativos. Perfilhos em estádio de desenvolvimento mais avançado, como o reprodutivo, estão com maior diferenciação morfológica e, portanto, são menos propensos às variações causadas por fatores que estimulam o crescimento. Nesse sentido, os coeficientes angulares das equações ajustadas para o perfilho vegetativo foram maiores que os coeficientes angulares das equações ajustadas para o perfilho reprodutivo (Tabelas 3 e 4).

\section{Conclusões}

A adubação nitrogenada ocasiona aumento do percentual de fibra em detergente neutro no colmo verde e no perfilho vegetativo, assim como do teor de proteína bruta nas folhas verdes e mortas, nos colmos verdes e nos perfilhos vegetativos e reprodutivos. Em pastos diferidos de Brachiaria decumbens cv. Basilisk, maior período de diferimento aumenta o percentual de fibra em detergente neutro e reduz o percentual de proteína bruta nos perfilhos vegetativos e reprodutivos. Em pastos de Brachiaria decumbens $\mathrm{cv}$. Basilisk diferidos por longos períodos e adubados com altas doses de nitrogênio, o valor nutritivo do perfilho vegetativo é semelhante ao do perfilho reprodutivo. No diferimento da pastagem, ações de manejo que resultem em maiores massas de lâmina foliar verde e número de perfilhos vegetativos contribuem para melhorar o valor nutritivo da forragem diferida.

\section{Referências}

CORSI, M.; NASCIMENTO JR., D. Princípios de fisiologia e morfologia de plantas forrageiras plicados no manejo de pastagens. In: PASTAGENS, FUNDAMENTOS DA EXPLORAÇÃO RACIONAL, 1994, Piracicaba. Anais... Piracicaba: FEALQ, 1994. p.15-48.

DIFANTE, G.S.; NASCIMENTO JR, D.; EUCLIDES, V.P.B. et al. Sward structure and nutritive value of tanzania guineagrass subjected to rotational stocking managements. Revista Brasileira de Zootecnia, v.38, n.1, p.9-19, 2009.

NASCIMENTO JR, D.; ADESE, B. Acúmulo de biomassa na pastagem. In: SIMPÓSIO SOBRE MANEJO ESTRATÉGICO DA PAStAGEM, 2., 2004, Viçosa, MG. Anais... Viçosa, MG: UFV, 2004. p.289-330.

PACIULLO, D.S.C.; GOMIDE, J.A.; QUEIROZ, D.S. et al. Composição química e digestibilidade "in vitro" de lâminas foliares e colmos de gramíneas forrageiras, em função do nível de inserção no perfilho, da idade e da estação de crescimento. Revista Brasileira de Zootecnia, v.30, n.3, p.964-974, 2001.

PACIULLO, D.S.C.; GOMIDE, J.A.; SILVA, E.A.M. et al. Características anatômicas da lâmina foliar e do colmo de gramíneas forrageiras, em função do nível de inserção no perfilho, da idade e da estação de crescimento. Revista Brasileira de Zootecnia, v.31, n.2, p.890-899, 2002.

PAULINO, M.F.; DETMANN, E.; ZERVOUDAKIS, J.T. Suplementos múltiplos para recria e engorda de bovinos em pastejo. In: SIMPÓSIO DE PRODUÇÃO DE GADO DE CORTE, 2., 2001, Viçosa, MG. Anais... Viçosa, MG: UFV, 2001. p.187-232.

PAULINO, M.F.P.; DETMANN, E.; VALADARES FILHO, S.C. Suplementação animal em pasto: energética ou proteica? In: SIMPÓSIO SOBRE MANEJO ESTRATÉGICO DA PASTAGEM, 3., 2006, Viçosa, MG. Anais... Viçosa, MG: UFV, 2006. p.359-392.

PEDREIRA, C.G.S.; MELLO, A.C.L.; OTANI, L. O processo de produção de forragem em pastagens. In: REUNIÃO ANUAL DA SOCIEDADE BRASILEIRA DE ZOOTECNIA, 38., 2001, Piracicaba. Anais... Piracicaba: ESALQ, 2001, p.772-807.

SANTOS, E.D.G.; PAULINO, M.F.; QUEIROZ, D.S. et al. Avaliação de pastagem diferida de Brachiaria decumbens Stapf.:1. Características químico-bromatológicas da forragem durante a seca. Revista Brasileira de Zootecnia, v.33, n.1, p.203-213, 2004.

SANTOS, M.E.R.; FONSECA, D.M.; EUCLIDES, V.P.B. et al. Valor nutritivo da forragem e de seus componentes morfológicos em pastagens de Brachiaria decumbens diferida. Boletim de Indústria Animal, v.65, n.4, p.303-311, 2008.

SANTOS, M.E.R.; FONSECA, D.M.; EUCLIDES, V.P.B. et al. Produção de bovinos em pastagens de capim-braquiária diferidas. Revista Brasileira de Zootecnia, v.38, n.4, p.635-642. 2009a.

SANTOS, M.E.R.; FONSECA, D.M.; BALBINO, E.M. et al. Capimbraquiária diferido e adubado com nitrogênio: produção e características da forragem. Revista Brasileira de Zootecnia, v.38, n.4, p.650-656, 2009b. 
SANTOS, M.E.R.; FONSECA, D.M.; BALBINO, E.M. et al. Caracterização de perfilhos em pastos de capim-braquiária diferidos e adubados com nitrogênio. Revista Brasileira de Zootecnia, v.38, n.4, p.643-649, 2009c.

SANTOS, M.E.R.; FONSECA, D.M.; EUCLIDES, V.P.B. et al. Características estruturais e índice de tombamento de Brachiaria decumbens cv. Basilisk em pastagens diferidas. Revista Brasileira de Zootecnia, v.38, n.4, p.626-634, 2009d.

SANTOS, P.M. Aspectos fisiológicos e metabólicos da nutrição nitrogenada de plantas forrageiras. In: SIMPÓSIO SOBRE
MAnejo DA PAStagem, 21., 2004, Piracicaba. Anais... Piracicaba: FEALQ, 2004. p.139-154.

SILVA, D.J.; QUEIROZ, A.C. Análise de alimentos: métodos químicos e biológicos. 2.ed. Viçosa, MG: Universidade Federal de Viçosa, 2002. 235p.

UNIVERSIDADE FEDERAL DE VIÇOSA - UFV. SAEG - Sistema de análises estatísticas e genéticas. Versão 8.1. Viçosa, MG: 2003. (Apostila).

VAN SOEST, P.J. Nutritional ecology of the ruminant. 2.ed. Cornell University Press, 1994. 476p. 